Research Article

\title{
Gas Pressure Effect on Sand Collapse in Kinetic Zone of Lost-Foam Casting
}

\author{
Joo Mae Jeon, ${ }^{1}$ Soo Jo Lee, ${ }^{2}$ Kyeong Hwan Choe, ${ }^{3}$ and Jeung-Soo Huh ${ }^{1}{ }^{1}$ \\ ${ }^{1}$ School of Materials Science and Engineering, Kyungpook National University, Daegu 41566, Republic of Korea \\ ${ }^{2}$ Research Center, Korea Evaporative Pattern Casting Company Limited, Kyungsangbuk-do 38909, Republic of Korea \\ ${ }^{3}$ Research Institute of Advanced Manufacturing Technology, Korea Institute of Industrial Technology, Incheon 21999, Republic \\ of Korea \\ Correspondence should be addressed to Jeung-Soo Huh; jshuh@knu.ac.kr
}

Received 12 March 2020; Accepted 8 April 2020; Published 25 April 2020

Academic Editor: Candido Fabrizio Pirri

Copyright (c) 2020 Joo Mae Jeon et al. This is an open access article distributed under the Creative Commons Attribution License, which permits unrestricted use, distribution, and reproduction in any medium, provided the original work is properly cited.

\begin{abstract}
Pressure of the kinetic zone is an essential factor for making defect-free castings in lost-foam casting process. The extremely high pressure causes many problems, such as reducing the melt velocity and inclusion of residual decomposition of the pattern in the castings, and very low pressure causes sand collapse. Therefore, the minimum gas pressure for preventing sand collapse is required. When the minimum gas pressure can be predicted, computer simulation becomes possible. Successful computer simulations can help reduce the number of trials and the lead time while designing new casting products. A preliminary sand experiment was conducted to predict the gas pressure and reduce the number of actual casting experiments. In this preliminary sand experiment, compressed air was used instead of gas in the kinetic zone. A new mathematical equation was proposed from the results of the preliminary sand experiment. The void ratio of the sand effect on the minimum gas pressure was included in the equation. An actual casting experiment was conducted by melting nodular cast iron to verify this equation. In the actual casting experiment, pressure of the kinetic zone in front of the metal tip was directly measured. The results obtained from the preliminary sand experiment and the actual casting experiment validated the equation.
\end{abstract}

\section{Introduction}

In the last three decades, lost-foam casting process (LFC) has been widely adopted to manufacture complex parts without the need for a core. The first step is making the pattern of the desired shape, which molds the expanded polystyrene beads, and the foam pattern is placed in a sand flask, and unbonded sand is poured around the pattern and compacted by vibration. Finally, the molten metal is poured, and the melt is replaced with the space occupied by the solid foam pattern, resulting in the desired cast products. The lost-foam casting process has several advantages [1-3] which allow the casting of complex shapes because the molten metal is poured without removing the pattern. Moreover, the use of dry sand without coking force and a resin-containing core reduces the manufacturing and waste treatment costs. Furthermore, no harmful gas is produced from the core. However, the lost- foam castings are susceptible to the generation of various defect forms. Many studies have been conducted to identify and solve the causes of casting defects [4-9]. If the residual foam pyrolysis is not completely discharged and the pressure balance in the mold is altered during the pouring operation, the sand may collapse, resulting in casting defects.

In lost-foam casting, an expanded polystyrene pattern is vaporized by the heat of the advancing metal melt, forming a gas gap in front of the metal tip. The gas gap is called the kinetic zone [10]. The gas pressure in the kinetic zone has a significant role in preventing the sand collapse in contact with the kinetic zone [11] and in reducing the instability of the interface at the tip of the melt. Increasing the instability of the melt tip interface adversely affects product quality [12]. However, if the gas pressure reduces the speed of the molten metal, the pouring duration is long and casting defects, such as a metal fold, can occur. Because this gas 
pressure also prevents sand collapse, it should be maintained at a suitable level. The gas pressure of the kinetic zone can be predicted based on findings from previous studies $[8,12]$. The gas pressure depends on the cross-section of the sprue and ingate, the height of the pouring basin, the permeability of the sand, the density of the expandable polystyrene pattern, the pouring temperature, and the melting speed.

Several studies have been conducted to predict and simulate casting failures in lost-foam casting [8, 13-19]. However, limited research has been conducted to simulate sand collapse. Hence, further research is imperative to predict sand collapse using a computer before pouring the metal melt. Successful computer simulations can help to reduce the number of trials and reduce the lead time in the design of new casting products. In a prior study in this field, Shulyak [11] calculated the minimum gas pressure to prevent the sand from collapsing near the kinetic zone. However, this equation was not verified by real casting experiments.

The aim of this study is to predict the minimum gas pressure needed to prevent sand from collapsing near the kinetic zone. A new model was proposed to predict the minimum gas pressure, and a mathematical equation was derived from this model. A preliminary sand experiment was conducted to verify this equation. The purpose of the preliminary sand experiment was to reduce the number of actual casting experiments. Actual casting experiments were carried out by melting cast iron to verify the model. In the actual casting experiment, the pressure of the kinetic zone in front of the metal tip was measured directly.

\section{Experimental Procedure}

The present experimental study was conducted in two stages. First, to reduce costs and time, we designed a special experimental device that could simulate the actual casting situation instead of actual casting, thus simulating the sand collapse in the kinetic zone. The second is the actual casting experiment.

2.1. Preliminary Sand Experiment. A test apparatus was specially designed to simulate the minimum gas pressure required to prevent sand collapse in the kinetic zone, as shown in Figure 1.

Both ends of the $80 \mathrm{~mm}$ diameter elbow acrylic (1) were bonded to each of the $80 \mathrm{~mm}$ diameter acrylic discs $(4,5)$. A hole, which is $50 \mathrm{~mm}$ in diameter, was made in the center of these two discs. An acrylic pipe (2) of $50 \mathrm{~mm}$ diameter was inserted approximately $100 \mathrm{~mm}$ into the acrylic disc (5). The pipe (2) was blocked on one side and not on the other. A square-shaped $10 \mathrm{~mm} \times 10 \mathrm{~mm}$ hole (6) was at the end of the blocked side of the pipe (2). A $50 \mathrm{~mm}$ diameter acrylic pipe (3) with one end blocked was bonded with the disc (4) on the other side of the elbow acrylic (1). At the end (12) of the tube (3), a hose for the inlet for compressed air with a regulating valve (7) and a regulator (8) was installed. A high-precision pressure transducer $(\mathrm{PT}, 9)$, which was manufactured by the Sensor System Technology Company (PSH model), was

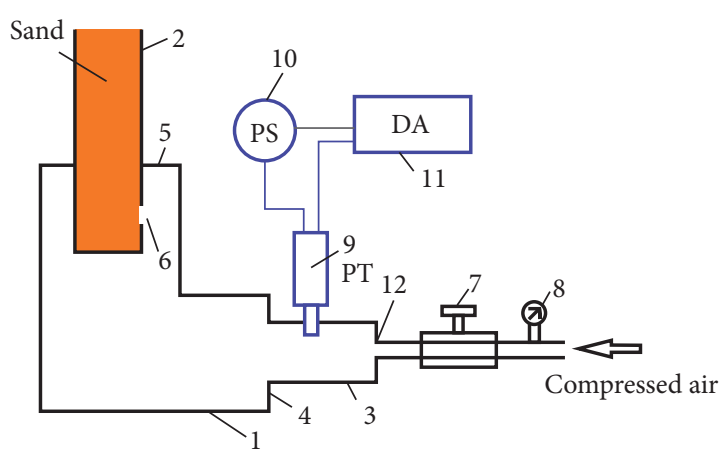

FIgURE 1: Schematic layout for measuring the sand collapse pressure. PT, pressure transducer; DA, data acquisition system; PS, power supply.

installed to measure the air pressure inside the elbow acrylic (1) at the pipe (3). The measurement range was $0-100 \mathrm{kPa}$ with a precision of \pm 0.15 . The PT was connected to a $24 \mathrm{~V}$ direct current power supply (PS, 10). When the pressure changed, this PT output current had a range of $4-20 \mathrm{~mA}$, that is, it gave $4 \mathrm{~mA}$ at atmospheric pressure and $20 \mathrm{~mA}$ at $100 \mathrm{kPa}$. A data acquisition system (DA, 11) manufactured by Graphtech Corporation (GL840 model) was connected to receive data from the pressure transducer $(\mathrm{PT}, 9)$. The data acquisition system had 20 channels, and each channel could receive five data points per second.

After the pipe (2) was separated from the disc (5), the hole (6) was closed with masking tape. After filling the pipe (2) with sand to the desired height, the masking tape was removed while the pipe (2) was inclined at $30^{\circ}$ to the ground and inserted into the hole of the disc (5). Because the sand had a repose angle of approximately $36^{\circ}$, it was prevented from pouring out even after removing the masking tape. With the pipe (2) tilted, the regulating valve (7) was opened to let the compressed air flow, and then the experimental apparatus was rotated so that the pipe (2) was vertical. The pressure of the compressed air in the elbow acrylic (1) was high enough so that the sand did not flow down even when the pipe (2) was vertical. By slowly closing the regulating valve (7) and slowly reducing the internal pressure of the elbow acrylic (1), the sand flowed out of the hole (6). The pressure at this time was read in a data acquisition system (DA, 11).

2.2. Actual Casting Experiment. An actual casting experiment was conducted to investigate the gas pressure and the sand collapse in the kinetic zone during lost-foam casting, as shown in Figure 2.

A square flask made of an iron plate was placed on a vibrating table and filled with dry sand up to a suitable height. The grain distribution of this sand is summarized in Table 1. Because the dried sand used in this experiment had no binder, it could only be compacted by flask vibration.

A sprue, runner, and gate were bonded to the expanded polystyrene pattern to form a cluster, which was placed on the compacted sand. After the sand was refilled and the flask was vibrated to compact the sand, the pouring basin was 


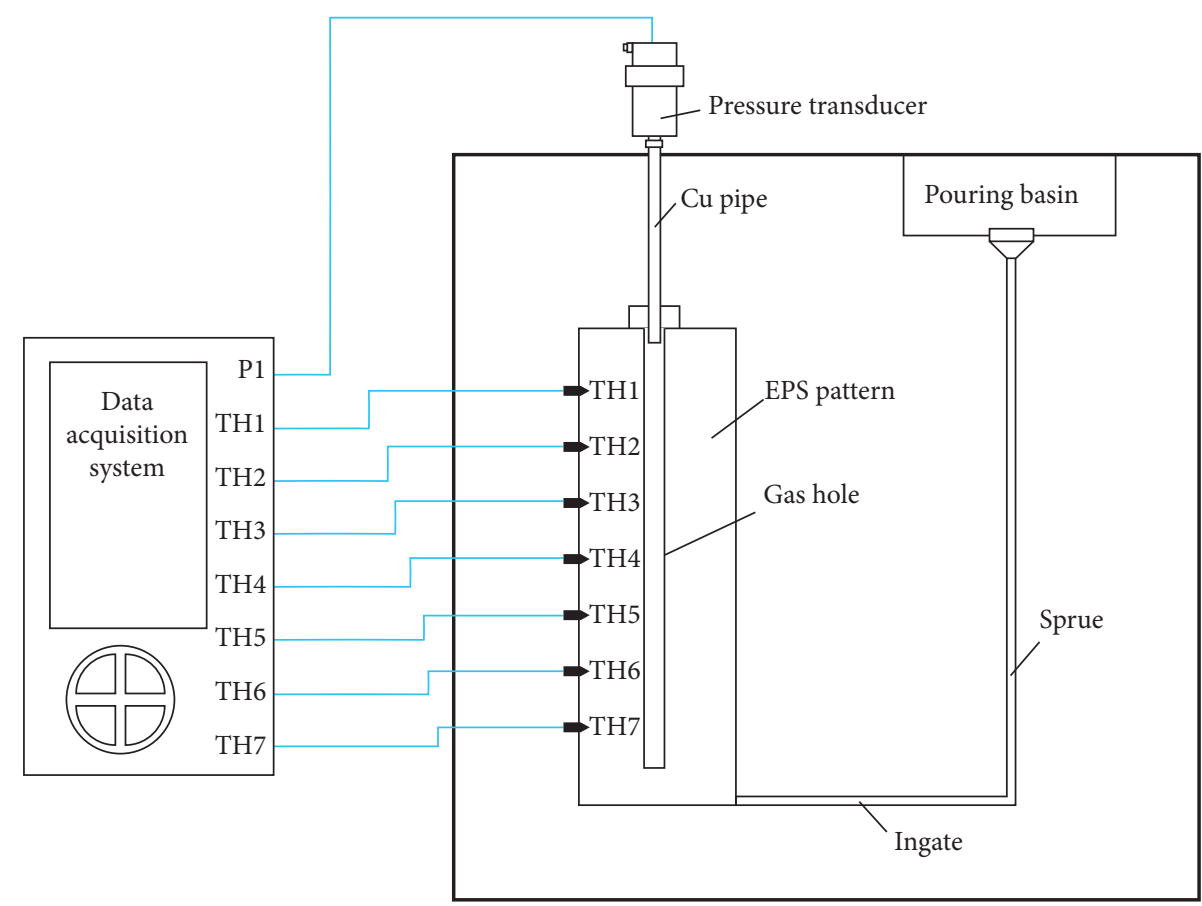

(a)

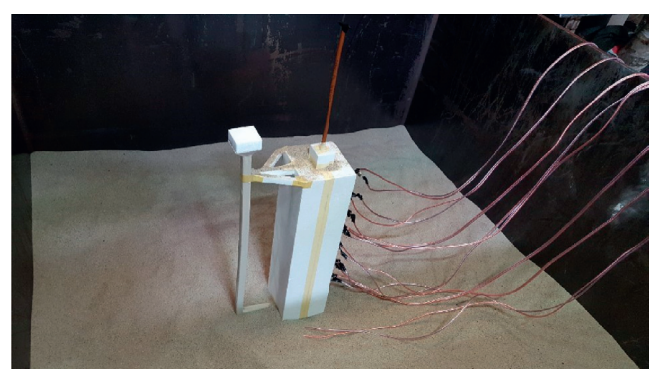

(b)

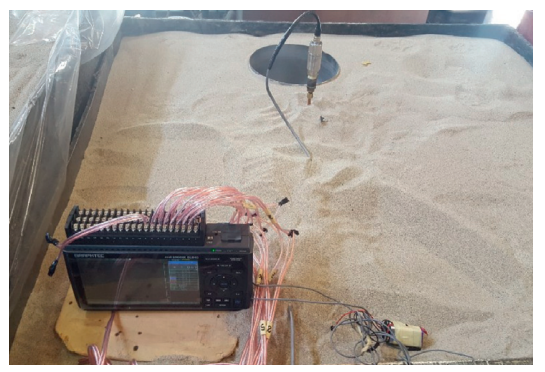

(c)

FIGURE 2: Schematic and photographs of the setup for measuring the kinetic zone pressure. (a) Schematic illustration of the actual casting experiment, (b) photograph showing before sand compaction, and (c) photograph showing the state before the pouring.

TABLE 1: Grain distribution of dry sand used as molding sand in this study.

\begin{tabular}{lccccccccc}
\hline Mesh no. & 30 & 40 & 50 & 70 & 100 & 140 & 200 & 270 & Pan \\
\hline Wt.\% & 7.25 & 38.28 & 40.32 & 10.69 & 2.90 & 0.51 & 0.04 & 0.01 & 0.00 \\
\hline
\end{tabular}

placed on top of the sprue. Because of the small crosssectional area of the ingate, a single-bottom ingate could not be fixed to the specimen or the sprue. The upper part was connected to an expanded polystyrene bar to ensure contact with the specimen and the sprue. The expanded polystyrene bar was then removed after the sand was filled to the bottom of the bar. Iron scrap and pig iron were melted at an appropriate ratio in an electric induction furnace. Spheroidizing treatment was performed using the inoculant and spheroidizer described in Tables 2 and 3, respectively, to obtain nodular cast iron, followed by molten metal pouring at a constant temperature $\left(1450^{\circ} \mathrm{C}\right)$ to reduce the experimental variables. The chemical composition of the molten metal is shown in Table 4. R-type thermocouples
TABLE 2: Chemical composition of the inoculant.

\begin{tabular}{lccccc}
\hline Element & $\mathrm{Si}$ & $\mathrm{P}$ & $\mathrm{S}$ & $\mathrm{Al}$ & $\mathrm{Fe}$ \\
\hline Wt.\% & 71.3 & 0.03 & 0.02 & 1.80 & Balance \\
\hline
\end{tabular}

TABle 3: Chemical composition of the spheroidizer.

\begin{tabular}{lcccccc}
\hline Element & $\mathrm{Mg}$ & $\mathrm{Ca}$ & R.E. & $\mathrm{Si}$ & $\mathrm{Al}$ & $\mathrm{Fe}$ \\
\hline Wt.\% & 5.28 & 2.06 & 2.04 & 46.85 & 0.76 & Balance \\
\hline
\end{tabular}

TABle 4: Chemical composition of the melt used in this study.

\begin{tabular}{lcccccc}
\hline Element & $\mathrm{C}$ & $\mathrm{Si}$ & $\mathrm{Mn}$ & $\mathrm{Mg}$ & $\mathrm{S}$ & $\mathrm{Fe}$ \\
\hline Wt.\% & $3.6-3.4$ & $2.3-2.5$ & $<0.5$ & $<0.05$ & $<0.02$ & Balance \\
\hline
\end{tabular}

(TH1-TH7) made by Shijiazhuang Wanlixin Industrial Company Limited were installed at $5 \mathrm{~cm}$ intervals in the longitudinal direction of the expanded polystyrene pattern to estimate the kinetic zone position, as shown in 
Figure 2(b). The seven thermocouples divided the pattern into eight sections along the longitudinal direction. These thermocouples were installed to measure the time at which the kinetic zone passed through the positions of the thermocouples. Very thin thermocouples with a $0.5 \mathrm{~mm}$ diameter were used to increase the temperature sensitivity. They were connected to a data acquisition system (GL840, Graphtech Co., Yokohama, Japan) by electric cables for continuous data storage every $0.2 \mathrm{~s}$.

The rectangular expanded polystyrene pattern used had a cross-sectional area of $10 \mathrm{~cm} \times 10 \mathrm{~cm}$ with a $40 \mathrm{~cm}$ height. The density of the expanded polystyrene pattern was $0.03 \mathrm{~g} /$ $\mathrm{cm}^{3}$. In the center of the expanded polystyrene pattern, a longitudinal gas hole, which was a square bar-shaped vacant space, was created for transferring the gas of the kinetic zone to the pressure transducer. The cross-sectional area of the gas hole was $0.7 \mathrm{~cm} \times 0.7 \mathrm{~cm}$. The gas hole was connected to a copper pipe with $0.6 \mathrm{~cm}$ in diameter. The copper pipe was connected to the high-precision pressure transducer, as shown in Figure 2(a).

In this study, the cross-sectional area of the sprue and ingate and the height of the pouring basin were changed to obtain various gas pressures in the kinetic zone in each test. The shape of the sprue and ingate was square. By changing the length of one side to $1 \mathrm{~cm}, 1.5 \mathrm{~cm}$, and $2 \mathrm{~cm}$, the crosssectional area of the sprue and ingate was changed. The ingate was positioned as the bottom gate for the smooth movement of the kinetic zone. The height of the pouring basin was $60 \mathrm{~cm}$ and $75 \mathrm{~cm}$ from the bottom of the specimen. In this study, the casting conditions were changed to change the gas pressure in the kinetic zone; however, the influence of the casting parameters on the gas pressure was not considered because it is beyond the scope of this study.

2.3. Density and Voids of the Sand-Measuring Experiment. The apparent density of the sand and void ratio of the sand were measured. The testing cylinder was filled with sand to a certain height and was vibrated. Then, the sand volume was measured to calculate its apparent density $\left(\gamma_{\mathrm{p}}\right)$ and void ratio. The measuring cylinder was filled with water before weighing. The void ratio $\left(e_{s}\right)$ was calculated as follows:

$$
\begin{gathered}
e_{\mathrm{s}}=\frac{V_{\mathrm{w}}}{V_{\mathrm{s}}}, \\
\gamma_{\mathrm{p}}=\frac{W_{\mathrm{w}}}{V_{\mathrm{s}}},
\end{gathered}
$$

where $V_{\mathrm{s}}$ is the sand volume and $V_{\mathrm{w}}$ and $W_{\mathrm{w}}$ are the volume and weight of water that has completely penetrated the sand void, respectively.

\section{Results and Discussion}

3.1. Preliminary Sand Experiment. The results of the preliminary sand experiment are shown in Figure 3 . The sand collapse pressure $\left(P_{\text {sand }}\right)$ values increase with the sand height $(z)$ from the hole (6) to the sand surface. Simple regression analysis was performed to derive the equations for the sand

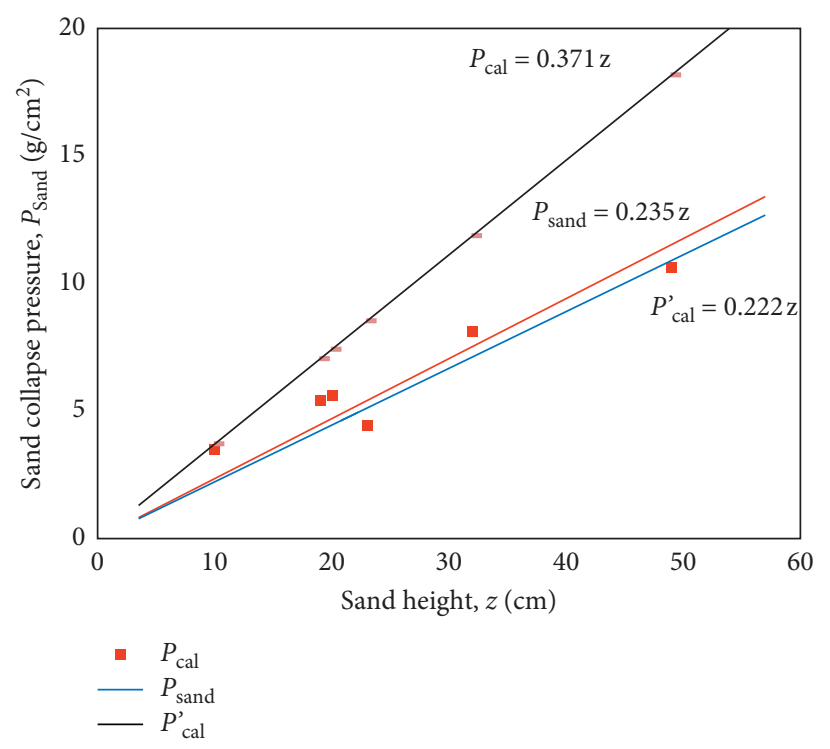

FIgURE 3: Comparison of the sand collapse pressure obtained by the preliminary sand experiment and calculated by Shulyak's model and the model suggested in this study. $\mathrm{P}_{\text {sand }}$ : measured pressure from preliminary sand experiment; $\mathrm{P}_{\text {cal }}$ : calculated from Shulyak's model; $\mathrm{P}_{\text {cal }}$ : calculated from suggested model.

height $(z)$ and the sand collapse pressure $\left(P_{\text {sand }}\right)$ and to verify the statistical significance of the derived equations. The null hypothesis is that the regression coefficient for the sand height corresponding to the slope of the equation was zero. The results of simple regression analysis are presented in Table 5 .

The regression equation is shown in equation (2). The sand height can be explained as $98.1 \%$ of the total sand pressure variation. The regression coefficient for the sand height $(z)$ was 0.235 . Because the level of significance is $p<0.001$, this regression coefficient is statistically significant at the $95 \%$ confidence level:

$$
P_{\text {sand }}=0.235 z \text {. }
$$

During the pouring of the metal melt, a kinetic zone is formed between the molten metal and the expanded polystyrene pattern (Figure 4).

If the flask is filled with fluid instead of sand in Figure 4, the vertical $\left(P_{\mathrm{V}}\right)$ and horizontal $\left(P_{\mathrm{H}}\right)$ stress components inside the fluid will be the same. However, because sand is a powder, internal friction occurs and, thus, the vertical components would not be transmitted in the horizontal direction fully. In this case, the horizontal sand pressure near the kinetic zone can be expressed as follows:

$$
P_{\mathrm{H}}=K P_{\mathrm{V}} \text {, }
$$

where $K$ is the coefficient of the earth pressure and can be expressed as per Ikenaga's work [20]:

$$
K=\tan ^{2}\left(45-\frac{\varnothing}{2}\right)
$$

Shulyak argued that a minimum gas pressure $\left(P_{\text {cal }}\right)$ is required to prevent sand from collapsing in the kinetic zone [11]: 
TABLE 5: Simple regression report.

\begin{tabular}{lccccc}
\hline $\begin{array}{l}\text { Prophetic } \\
\text { variable }\end{array}$ & $B$ & $\begin{array}{c}\text { Standard } \\
\text { error }\end{array}$ & $t$ & $R^{2}$ & Significance \\
\hline Sand height $(z)$ & .235 & .014 & 16.232 & .981 & .000 \\
\hline
\end{tabular}

$p<.001$.

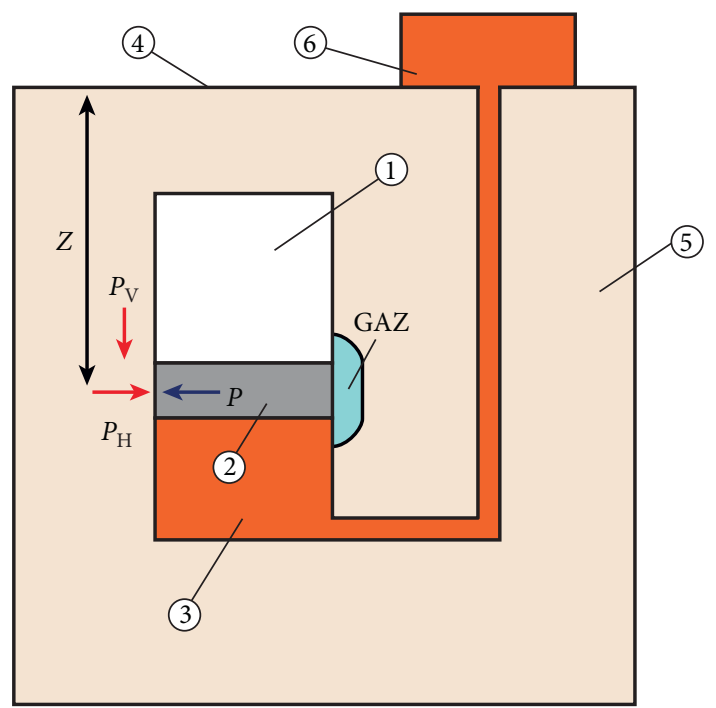

FIgURE 4: Schematic illustration of lost-foam casting process. 1, expanded polystyrene pattern; 2 , kinetic zone; 3 , molten metal; 4 , flask; 5 , dried sand; 6 , pouring basin; $P$, gas pressure in kinetic zone; $z$, height from kinetic zone to sand; $P_{\mathrm{V}}$, vertical sand pressure; $P_{\mathrm{H}}$, horizontal sand pressure; GAZ, gas affected zone.

$$
P_{\text {cal }}=\gamma_{\mathrm{p}} z \tan ^{2}\left(45^{\circ}-\frac{\varnothing}{2}\right)
$$

where $P_{\text {cal }}$ is the minimum gas pressure (in $\mathrm{g} / \mathrm{cm}^{2}$ ) that could prevent the collapse, $\gamma_{p}$ is the apparent density of the sand (in $\mathrm{g} / \mathrm{cm}^{3}$ ), and $z$ is the distance from the mold top to the kinetic zone (in $\mathrm{cm}$ ). This equation assumes that the gas does not enter the sand.

The measured $\gamma_{\mathrm{p}}$ and $\varnothing$ values were $1.43 \mathrm{~g} / \mathrm{cm}^{3}$ and $36^{\circ}$, respectively. By substituting these values in equation (5), we obtain the following:

$$
P_{\text {cal }}=0.371 z \text {. }
$$

As shown in Figure 3, the sand collapse pressure $\left(P_{\text {sand }}\right)$ was lower than the pressure $\left(P_{\text {cal }}\right)$ calculated using equation (6).

Shulyak's idea is that unbonded sand, which accumulates as high as $z$, loads the sand on the surface of the gas layer with its weight, causing the sand on the surface to collapse. The gas of the kinetic zone applies the pressure to only the grains of sand on the surface of the kinetic zone to prevent sand from collapsing, as shown in Figure 5(a). However, practically, the gas enters the inner sand through the voids, which is between the sand grains, and exerts an outward force on the grains of sand, as shown in Figure 5(b). For this reason, the vertical and horizontal pressures of the sand are simultaneously reduced. The greater the voids of the sand, the greater the decrease in the sand pressure. Hence, at a lower pressure than that found in equation (6), sand can withstand collapse.

A new mathematical model was proposed in this study to explain this phenomenon. Figure 6 illustrates the distribution of the gas pressure near the kinetic zone. The gas in the kinetic zone penetrates the voids between the sand grains. The penetrating gas exerts a force that pushes the grains of sand outward, creating a gas-affected zone (GAZ).

Many sand plates, with a thickness equal to the average particle diameter $(t)$, are stacked to form the gas-affected zone, as shown in Figure 6. Figure 6(a) shows a rectangular sand block with a small cross-section near the kinetic zone. Suppose a sand layer is made by stacking several plates of sand with a certain thickness, the gas enters the sand plates through the voids from the outer sand plate in contact with the kinetic zone to the inner sand plate. Because the flow of gas is resisted by the grains of sand, the gas pressure of the inner sand plate becomes smaller than that of the outer sand plate. It is assumed that the gas pressure $\left(P_{1}\right)$ of the inner sand plate is reduced by the volume fraction of sand than that of the outer sand plate $\left(P_{0}\right)$. For this reason, when the gas pressure $\left(P_{\text {cal }}^{\prime}\right)$ acts on the sand plate on the outer surface, the pressure acting on the next inner sand plate is $e_{\mathrm{s}} P_{\mathrm{cal}}^{\prime}$, followed by $e_{\mathrm{s}}^{2} P_{\mathrm{cal}}^{\prime}$. Here, $e_{\mathrm{s}}$ is the void ratio of the sand. The gas pressure distribution is shown in Figure $7(\mathrm{~b})$. Hence, the gas pressure on the entire sand plate is as follows:

$$
P_{\mathrm{cal}}^{\prime}+e_{\mathrm{s}}^{1} P_{\mathrm{cal}}^{\prime}+e_{\mathrm{s}}^{2} P_{\mathrm{cal}}^{\prime}+e_{\mathrm{s}}^{3} P_{\mathrm{cal}}^{\prime}+\cdots+e_{\mathrm{s}}^{n} P_{\mathrm{cal}}^{\prime},
$$

where $n$ refers to the $n$-th sand plate and $n$ is related to the gas penetration distance $(l)$, which is given as follows:

$$
l=n t
$$

where the void ratio of sand $\left(e_{\mathrm{s}}\right)$ is assumed to be uniform for all sand plates. At the start of sand collapse, the equation of force balance at the boundary between the sand and the kinetic zone is

$$
P_{\mathrm{cal}}^{\prime}\left(1+e_{\mathrm{s}}^{1}+e_{\mathrm{s}}^{2}+e_{\mathrm{s}}^{3}+\cdots e_{\mathrm{s}}^{n}\right)=\gamma_{\mathrm{p}} z \tan ^{2}\left(45^{\circ}-\frac{\varnothing}{2}\right),
$$

where the gas pressure in the kinetic zone is equal to the horizontal pressure caused by the sand weight.

Equation (9) can be arranged as follows, using the sum of the isometric progression:

$$
P_{\mathrm{cal}}^{\prime} \frac{\left(1-e_{\mathrm{s}}^{(n+1)}\right)}{\left(1-e_{\mathrm{s}}\right)}=\gamma_{\mathrm{p}} z \tan ^{2}\left(45^{\circ}-\frac{\varnothing}{2}\right) \text {. }
$$

Under the condition $e_{\mathrm{s}}<0.7$ and $n>10$,

$$
\frac{\left(1-e_{\mathrm{s}}\right)}{\left(1-e_{\mathrm{s}}^{(n+1)}\right)} \cong\left(1-e_{\mathrm{s}}\right) \text {. }
$$

Because these conditions can be applied in the actual lost-foam casting process, equation (11) can be simplified as follows:

$$
P_{\mathrm{cal}}^{\prime}=\left(1-e_{\mathrm{s}}\right) \gamma_{\mathrm{p}} z \tan ^{2}\left(45^{\circ}-\frac{\varnothing}{2}\right)
$$




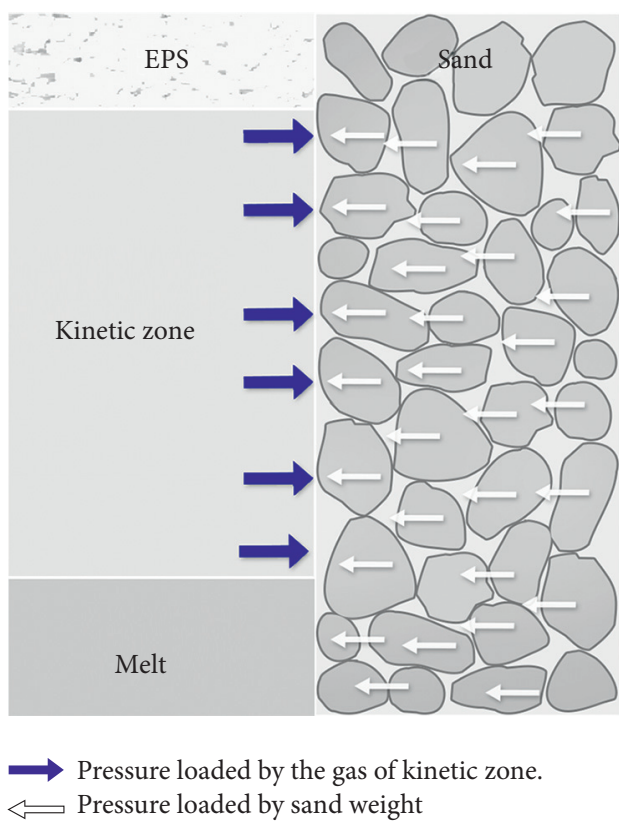

(a)

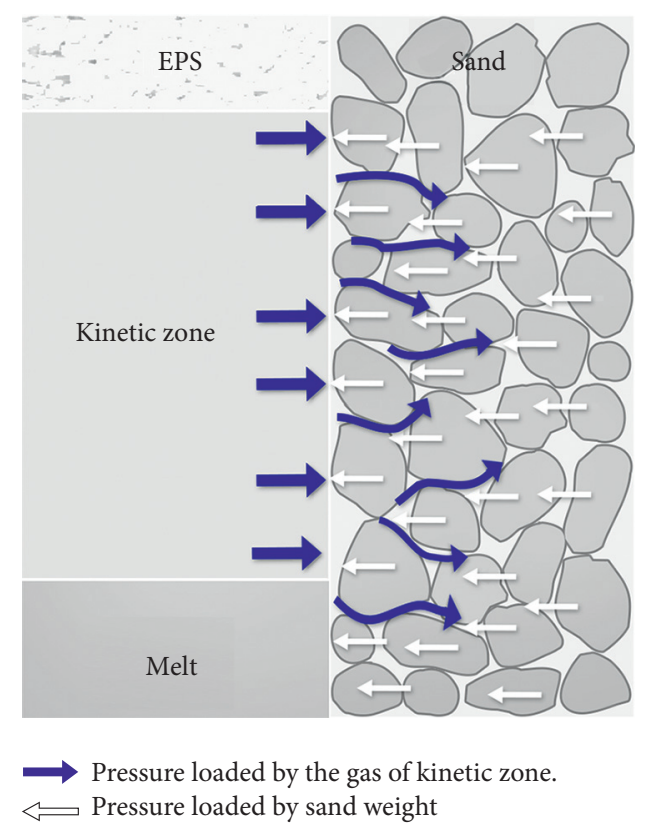

(b)

Figure 5: Schematic illustration showing the difference between the Shulyak model and the model suggested in this study. (a) Shulyak's model, the gas of the kinetic zone applies the pressure only to the grains of sand on the surface of the kinetic zone, and (b) the model proposed in this study, the gas of the kinetic zone simultaneously pushes the sand on the surface and inside.

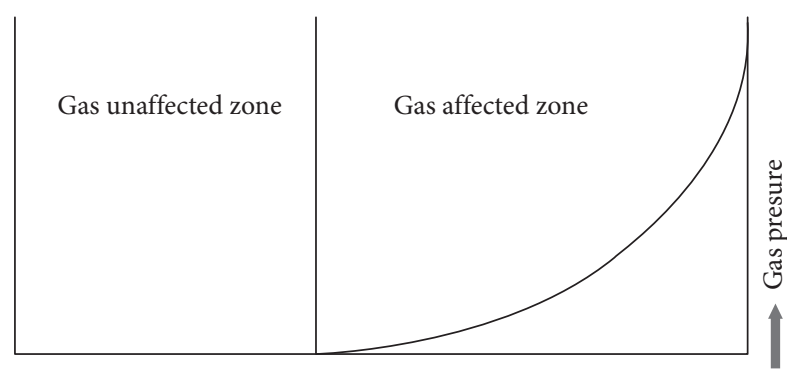

Distance from sand surface contacting with kinetic zone

(a)

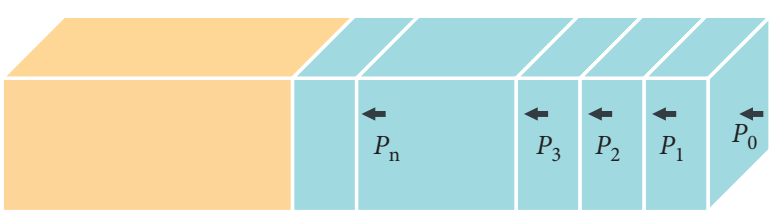

(b)

FIGURE 6: Schematic illustration showing (a) sand plate and (b) distribution of the gas pressure near the kinetic zone.

Equation (9) considers the voids of sand.

In this study, the $e_{\mathrm{s}}$ values were in the range of $0.39-0.42$, and the average was 0.4 . Substituting these values into equation (12), $P_{\text {cal }}^{\prime}$ can be modified as follows:

$$
P_{\text {cal }}^{\prime}=0.222 z \text {. }
$$

The result of the model suggested in this study showed better agreement than that of Shulyak's model, as seen in Figure 3.

There were some differences between the results of this study and those of Shulyak. The value calculated in this study was lower than that calculated by Shulyak because Shulyak did not consider sand voids. Compressed air prevents the surface sand grains from collapsing and pressurizes the grains inside, reducing the load on the surface sand grains. As a result, the pressure required to prevent surface sand collapsing was reduced.
3.2. Actual Casting Experiment. Figure 8 shows the results of the actual casting test, which measured the gas pressure during the pouring of the melted metal. Figure 7(a) shows that the sand collapses because of the lower gas pressure during the pouring. The location of the sand collapse $(z)$ in the casting was measured with a ruler. The gas pressure curves obtained in the actual casting experiment are shown in Figure 7(b). Most experiments exhibited similar gas pressure curves. The molten metal passed through a sprue with a small cross-sectional area from the pouring basin. Then, it passed through the ingate and, upon reaching the gas measurement connecting passage $(A$ in Figure $7(b))$, the gas pressure rose to $B$ and quickly dropped to $C$. When the pouring began, the expandable polystyrene pattern was rapidly vaporized because the molten metal moved at high speed from the pouring basin to the ingate. Because the time was not enough for the gas that was generated very quickly to 

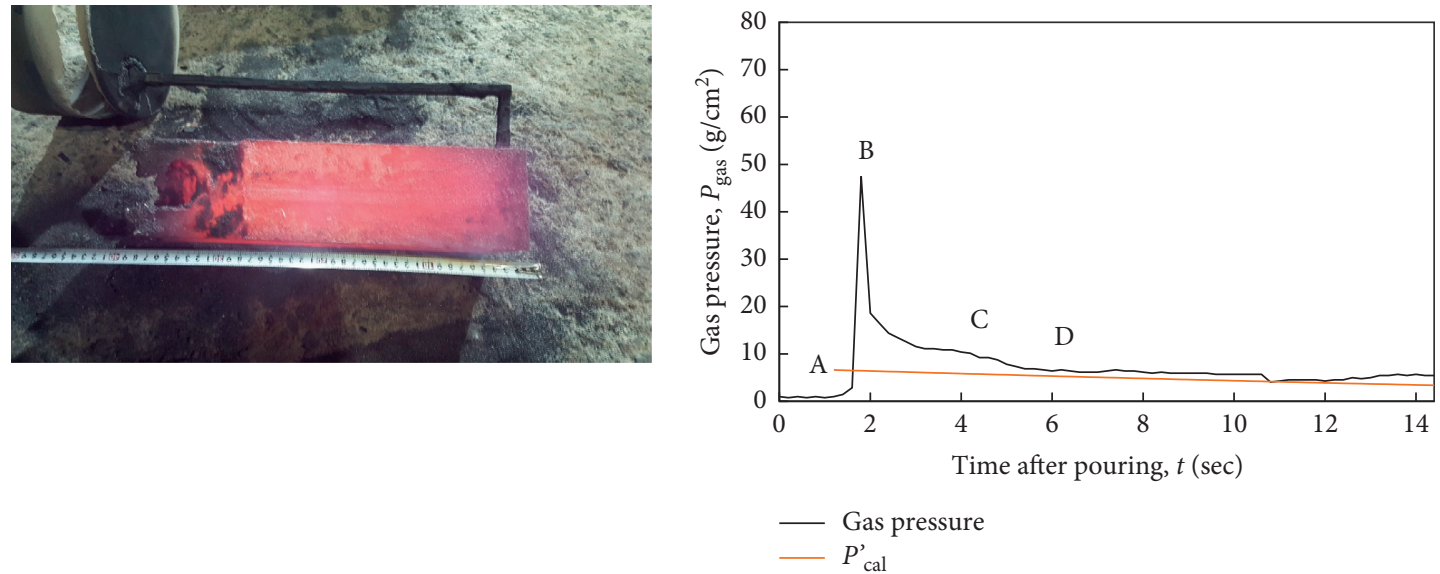

(a)

(b)

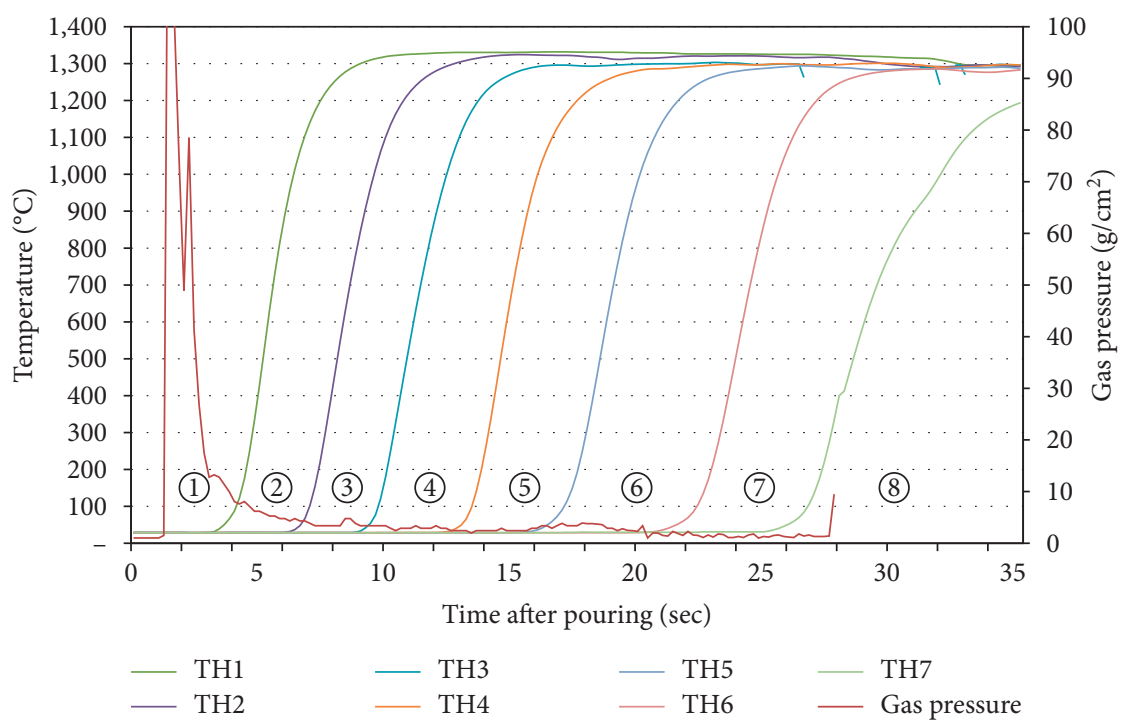

(c)

Figure 7: Gas pressure at the kinetic zone and temperature in the cast specimen during mold filling. The eight numbers in circles indicate the section between the thermocouple; (a) casting after the actual casting experiment; (b) gas pressure in the kinetic zone; and (c) gas pressure and temperature in the cast specimen during the actual casting experiment.

be discharged, the gas pressure increased in height. The highest pressure is shown in Figure $7(\mathrm{~b})$ as $B$. The pressure was high until $B$ and decreased instantly as the cross-section of the melted tip suddenly increased. At this time, it was stable up to $D$ for a period. As the pressure head decreased, which is the height from the top of the melt to the pouring basin, the gas pressure decreased. The curves of the temperatures in Figure 7(c) were obtained using a thermocouple. The temperature curves divided the gas curve into eight sections. The average pressure of the section where sand collapsed was used as the sand collapse pressure $\left(P_{\text {real }}\right)$.

The sand height and gas pressure at which the sand collapsed are shown in Figure 8. The two variables $\left(P_{\text {real }}, z\right)$ have a linear relationship similar to that in Figure 3. Simple regression analysis was performed to verify these measured values. The results of the simple regression analysis are presented in Table 6.
The regression equation is shown in equation (14); the sand height can be explained by $94.9 \%$ of the total gas pressure variation. Since the level of significance is $p<0.001$, this regression coefficient is statistically significant at the 95\% confidence level:

$$
P_{\text {real }}=0.225 z \text {, }
$$

$P_{\text {real }}$ and $P_{\text {cal }}{ }^{\prime}$ shows a similar linear relationship. However, the $R$-squared values were different, which means that the data obtained from the actual casting experiment are scattered more widely than from the preliminary sand experiment. This may be because there are more variables in the actual casting that are not explained than in the preliminary sand experiment. Therefore, equation (13) is expected to be useful for estimating the minimum pressure to prevent sand from collapsing before pouring. 


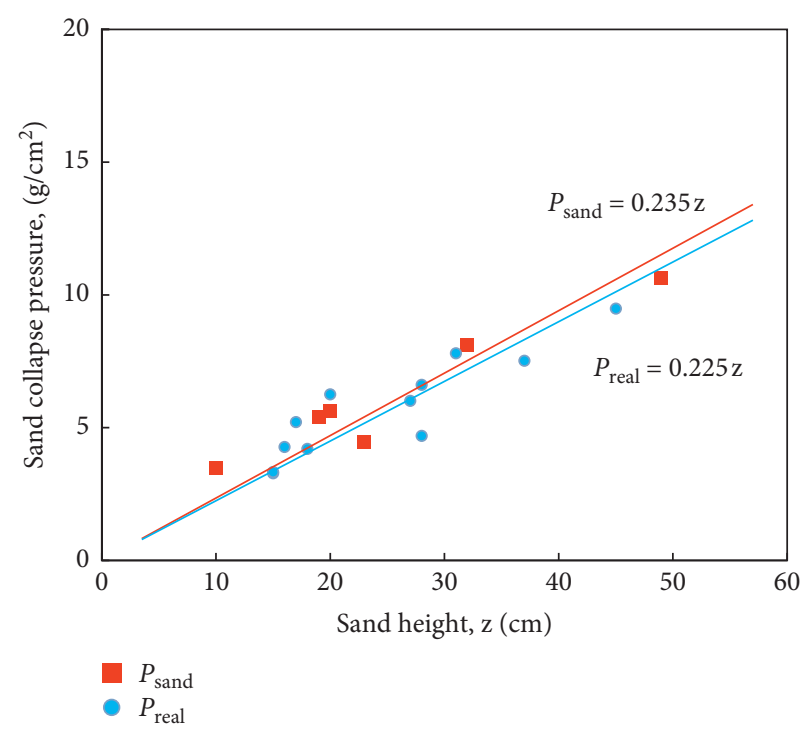

FIgURE 8: Comparison of the sand collapse pressure obtained by the preliminary sand and actual casting experiments. $\mathrm{P}_{\text {sand }}$ : measured pressure from preliminary sand experiment; $P_{\text {real }}$ : measured pressure from realistic casting.

TABLE 6: Simple regression report.

\begin{tabular}{lccccc}
\hline $\begin{array}{l}\text { Prophetic } \\
\text { variable }\end{array}$ & $B$ & $\begin{array}{c}\text { Standard } \\
\text { error }\end{array}$ & $t$ & $R^{2}$ & Significance \\
\hline Sand height $(z)$ & 0.225 & 0.010 & 21.682 & 0.949 & 0.000 \\
\hline$p<0.001$. & & & & &
\end{tabular}

\section{Conclusions}

An equation that predicts the minimum gas pressure of the kinetic zone for preventing sand collapse in lost-foam casting has been suggested. It was found that the gas pressure in the kinetic zone should be sufficiently high to prevent the collapse of sand. The gas pressure supports the sand on the surface in contact with the kinetic zone, thereby preventing collapse. Because the sand has no binder, it easily collapses by its own weight when the gas pressure is low. The gas pressure of the kinetic zone supports the surface sand grains from collapsing and pressurizes the grains inside, reducing the load on the surface sand grains. As a result, the minimum gas pressure required to prevent surface sand collapse reduces. Therefore, the larger the void ratio of the sand, the easier the gas permeates into the sand and the lower the minimum gas pressure required to prevent sand collapse.

In the casting experiment, the pressure of the kinetic zone in front of the metal tip was measured directly. The minimum gas pressure required to prevent sand collapse calculated by the equation presented in this study agrees with those from the preliminary sand experiment and the actual casting experiments. This equation is expected to be useful in estimating the minimum pressure to prevent sand collapse before pouring.

\section{Nomenclature}

$P_{\mathrm{V}}$ : Vertical stress components of sand

$P_{\mathrm{H}}$ : Horizontal stress components of sand

$P: \quad$ Gas pressure of kinetic zone

$K$ : Coefficient of earth pressure

$\varnothing: \quad$ The internal friction angle of sand

$P_{\text {cal }}$ : The minimum gas pressure calculated by Shulyak's model

$P_{\text {cal }}^{\prime}$ : $\quad$ The minimum gas pressure calculated by the model suggested in this study

$P_{\text {sand }}$ : The sand collapse pressure measured by the preliminary sand experiment

$P_{\text {real }}$ : The sand collapse pressure measured by the actual pouring experiments

l: $\quad$ Gas penetration distance

$t$ : The thickness of the sand plate

$\gamma_{\mathrm{p}}$ : The apparent density of the sand

$z$ : The height from the mold top to the kinetic zone

$e_{\mathrm{s}}$ : Void ratio of sand

$V_{s}$ : Sand volume

$V_{\mathrm{w}}$ : Volume of water that has completely penetrated into the sand void

$w_{\mathrm{w}}$ : Weight of water that has completely penetrated into the sand void.

\section{Data Availability}

The data used to support the findings of this study are available from the corresponding author upon request.

\section{Conflicts of Interest}

The authors declare that there are no conflicts of interest regarding the publication of this paper.

\section{Acknowledgments}

This study was sponsored by the Korea Evaporative Pattern Casting Company.

\section{References}

[1] Z. Fan, W. Jiang, F. Liu, and B. Xiao, "Status quo and development trend of lost foam casting technology," China Foundry, vol. 11, no. 4, pp. 296-307, 2014.

[2] J. Troxler Jr., "The prospects for lost foam in 1995," Transactions of the American Foundrymen's Society, vol. 98, pp. 371-378, 1990.

[3] E. J. Sikora, "Evaporative casting using expandable polystyrene patterns and unbonded sand casting techniques," Modern Casting, vol. 68, pp. 68-69, 1978.

[4] M. Hill, A. E. Vrieze, T. L. Moody et al., "Effect of metal velocity on defect formation in al LFCs," Transactions of the American Foundrymen's Society, vol. 106, pp. 365-374, 1998.

[5] W. D. Griffiths and M. J. Ainsworth, "Hydrogen pick-up during mould filling in the lost foam casting of Al alloys," Journal of Materials Science, vol. 47, no. 1, pp. 145-150, 2012.

[6] T. N. Chakherlou, Y. V. Mahdinia, and A. Akbari, "Influence of lustrous carbon defects on the fatigue life of ductile iron 
castings using lost foam process," Materials \& Design, vol. 32, no. 1, pp. 162-169, 2011.

[7] S. Mehta, S. Biederman, and S. Shivkumar, "Thermal degradation of foamed polystyrene," Journal of Materials Science, vol. 30, no. 11, pp. 2944-2949, 1995.

[8] S. Shivkumar, L. Wang, and B. Steenhoff, "Metallurgical quality of Aluminum castings produced by the Lost Foam process," American Foundrymen's Society, vol. 97, pp. 825836, 1989.

[9] O. E. Okorafor and C. R. Loper, "Metallurgical factors affecting the microstructure of expendable polystyrene pattern cast Al-4. 25Cu-1. 03Si," Transactions of the American Foundrymen's Society, vol. 90, pp. 285-295, 1982.

[10] X. J. Liu, R. C. Bhat, S. H. Bhavnani, and R. A. Overfelt, "Transport phenomena in the production and use of expanded polystyrene patterns in lost foam casting," Materials and Manufacturing Processes, vol. 22, no. 7-8, pp. 811-818, 2007.

[11] V. S. Shulyak, "Castings using gasifiable patterns," Russ Casting Production, vol. 8, pp. 356-358, 1968.

[12] W. D. Griffiths and M. J. Ainsworth, "Instability of the liquid metal-pattern interface in the lost foam casting of aluminum alloys," Metallurgical and Materials Transactions A, vol. 47, no. 6, pp. 3137-3149, 2016.

[13] X. J. Liu, S. H. Bhavnani, and R. A. Overfelt, "Simulation of EPS foam decomposition in the lost foam casting process," Journal of Materials Processing Technology, vol. 182, no. 1-3, pp. 333-342, 2007.

[14] S. H. M. Mirbagheri, J. R. Silk, and P. Davami, "Modelling of foam degradation in lost foam casting process," Journal of Materials Science, vol. 39, no. 14, pp. 4593-4603, 2004.

[15] D. A. Caulk, "A foam engulfment model for lost foam casting of aluminum," International Journal of Heat and Mass Transfer, vol. 49, no. 21-22, pp. 3831-3845, 2006.

[16] C. W. Hirt and M. R. Barkhudarov, "Predicting defects in lost foam castings," Modern Casting, vol. 92, pp. 31-33, 2002.

[17] X. Yao, S. Shivkumar, and X. Vao, "Mould filling characteristics in lost foam casting process," Materials Science and Technology, vol. 13, no. 10, pp. 841-846, 2013.

[18] O. Gurdogan, H. Huang, H. U. Akay, W. .W. Fincher, and V. E. Wilson, "Mold-filling analysis for ductile iron lost foam castings," Transactions of the American Foundrymen's Society, vol. 4, pp. 451-459, 1996.

[19] A. Charchi, M. Rezaei, S. Hossainpour, J. Shayegh, and S. Falak, "Numerical simulation of heat transfer and fluid flow of molten metal in MMA-St copolymer lost foam casting process," Journal of Materials Processing Technology, vol. 210, no. 14, pp. 2071-2080, 2010.

[20] A. Ikenaga, M. Kawamoto, and K. Tamura, "The pressure distribution in unbonded sand of the full mold process with reduced pressure," Japan Foundrymen's Society, vol. 60, pp. 524-528, 1988. 